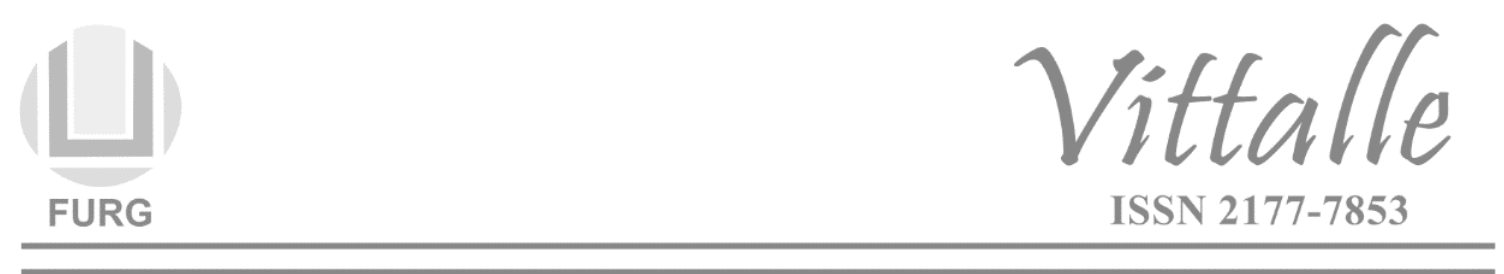

\title{
Distúrbios do Potássio
}

\author{
Eduardo Borges Gomes, Hugo Cataud Pacheco Pereira*
}

Faculdade de Medicina, Universidade Federal do Rio Grande, Rio Grande, RS, Brasil

\section{Palavras-chave: Hiperpotassemia; Hipopotassemia; Homeostase; Potássio.}

Keywords:

Hyperkalemia;

Hypokalemia;

Homeostasis; Potassium

\section{RESUMO}

O potássio é o íon mais abundante do corpo humano, concentrando-se no meio intracelular. Seu equilíbrio é fundamental para a homeostase, gerando graves repercussões metabólicas tanto a sua diminuição, quanto a sua elevação. Este capítulo apresenta as principais anormalidades e trará casos simulados para o leitor exercitar o conteúdo aprendido.

\section{Potassium Disorders}

\section{Introdução}

O potássio, representado por $\mathrm{K}+$, é o íon mais abundante do corpo humano (50 mEq/kg), estando aproximadamente $98 \%$ do seu total no compartimento intracelular (CIC) e, apenas, $2 \%$ no extracelular (CEC) $(2,3)$. Devido a essa intensa diferença entre os compartimentos, corrobora-se para a existência de um potencial elétrico nas membranas celulares, o que possibilita a excitabilidade dos nervos e das células musculares, incluindo os cardiomiócitos (1-4). Assim, espera-se que nos distúrbios calêmicos, os sistemas cardiovascular, nervoso e muscular sofram, constituindo muitas vezes numa das mais frequentes emergências clínicas $(1,2,4)$.

Visando evitar qualquer modificação na concentração sérica do potássio, diversos mecanismos orgânicos estão envolvidos nessa regulação. Veja o Quadro 1 a seguir (1-3):

\footnotetext{
*Autor correspondente: hcppaguia@ vetorial.net (Pereira H.C.P.)
} 
Quadro 1 - Principais mecanismos orgânicos envolvidos na regulação do potássio (1).

\section{$\beta_{2}$ - agonistas e catecolaminas}

Insulina

\section{Aldosterona}

\section{Equilíbrio Ácido-básico}

As catecolaminas, principalmente a adrenalina, atuam diretamente na bomba $\mathrm{Na}^{+} \mathrm{K}^{+}$- ATPase, estimulando-a para o ingresso de potássio. Por outro lado, os $\beta$-bloqueadores fazem com que o potássio plasmático aumente com a saída do íon intracelular.

Esse hormônio provoca o ingresso de potássio no meio intracelular, ativando a bomba $\mathrm{Na}^{+} \mathrm{K}^{+}$ - ATPase, independentemente do metabolismo da glicose. Assim, a insulina se torna um importante recurso no tratamento das hipercalemias, principalmente nas cetoacidoses diabéticas.

Atua no ducto coletor nos canais de sódio, fazendo com que o sódio seja reabsorvido à custa da secreção do potássio.

Visando o equilíbrio elétrico, em situações em que há hidrogênio em demasia no plasma (acidose), este é tamponado, intracelularmente, pela substituição de um próton por um sódio, por meio do trocador $\mathrm{Na}^{+}-\mathrm{H}^{+}$. Assim, a disponibilidade de sódio intracelular diminui, de modo que pode ser tão intenso a ponto de não haver biodisponibilidade para bomba $\mathrm{Na}^{+} \mathrm{K}^{+}$- ATPase realizar a troca de sódio por potássio, fazendo com que o potássio não saia do CEC, aumentando a concentração calêmica. Em contrapartida, em situações de alcalose, esse processo ocorre inversamente. Resumindo, em acidoses há um incremento de potássio sérico, enquanto nas alcaloses há uma diminuição.

Perceba que a as proteínas $\mathrm{Na}^{+} \mathrm{K}^{+}$- ATPase e trocador $\mathrm{Na}^{+}-\mathrm{H}^{+}$desempenham um papel crítico na regulação do potássio, que acaba sendo mediado pelos fatores recém mencionados. Ainda, o potássio possui uma íntima relação com o pH plasmático.

O rim está envolvido em outros mecanismos da homeostase calêmica. Este atua como protagonista em situações de sobrecarga que perduram por horas, sendo responsável por até $90 \%$ da excreção diária do íon (2,3). Dito isso, é importante destacar que pacientes que possuam a função renal prejudicada acabam tendo a eliminação do potássio principalmente pela via fecal, que fisiologicamente corresponde de 5 a $10 \%$ da excreção diária, enquanto nesses casos correspondem na excreção de até $25 \%$ do total ingerido (1). 
Vittalle - Revista de Ciências da Saúde v. 33, n. 1 (2021) 232-250

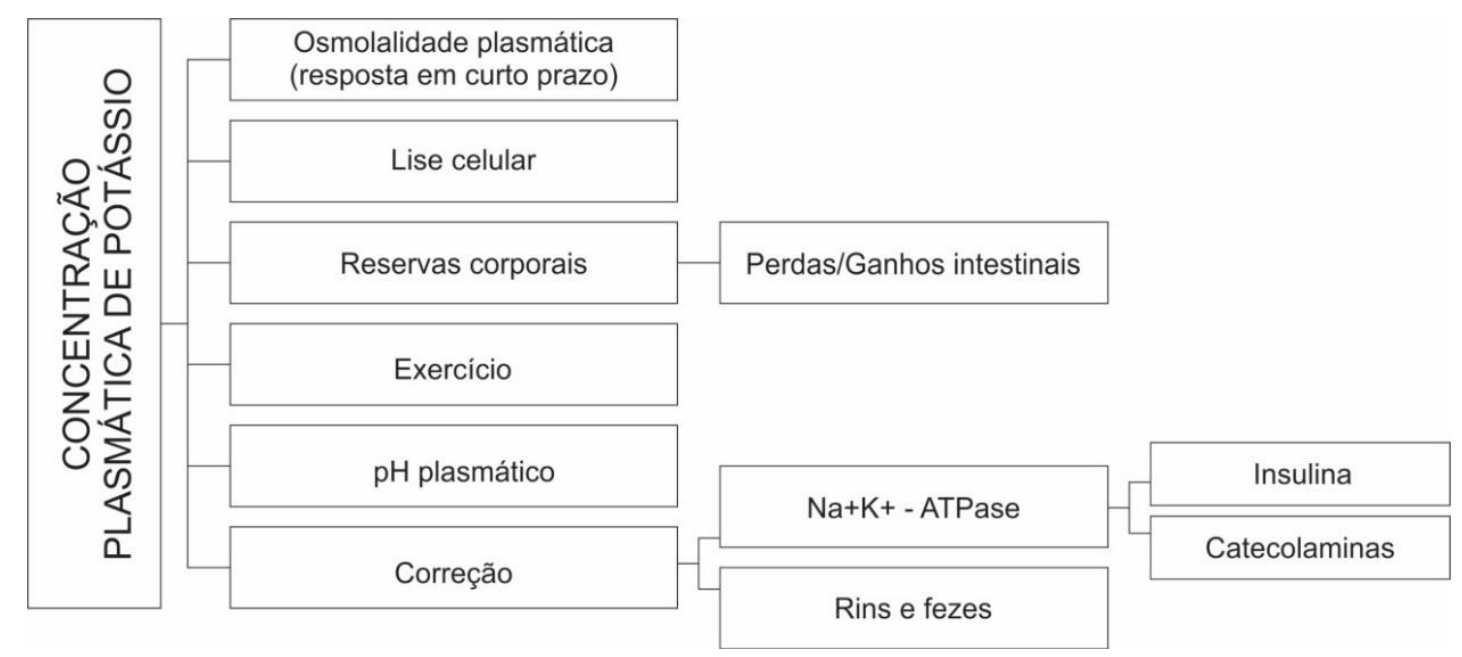

Figura 1 - Esquema do controle do potássio plasmático (1).

\section{Hipopotassemia}

\subsection{Definição}

A hipopotassemia ou hipocalemia é definida como concentração de potássio sérico $\left(\left[\mathrm{K}^{+}\right]\right)$inferior a $3,5 \mathrm{mEq} / \mathrm{L}(1,4,5)$. Quando se encontra de 2,5 a $3,0 \mathrm{mEq} / \mathrm{L}$, a hipopotassemia é classificada como moderada e abaixo de 2,5, como severa (1). Alguns autores estimam que a hipocalemia é o distúrbio eletrolítico mais comum, estando presente em até um quinto dos pacientes internados, sendo que a maioria apresenta a forma leve do distúrbio (1).

Estima-se que para cada $1 \mathrm{mEq} / \mathrm{L}$ abaixo de $4 \mathrm{mEq} / \mathrm{L}$ de potassemia, haja um déficit de 4 a $5 \mathrm{mEq} / \mathrm{kg}$. Apesar de não parecer muito, essas pequenas variações podem causar graves alterações dos sistemas cardiovascular e neuromuscular $(1-3,5,6)$.

\subsection{Etiologia}

O Quadro 2 a seguir apresenta, resumidamente, as principais causas da diminuição da potassemia (1): 
Quadro 2 - Causas de hipocalemia.

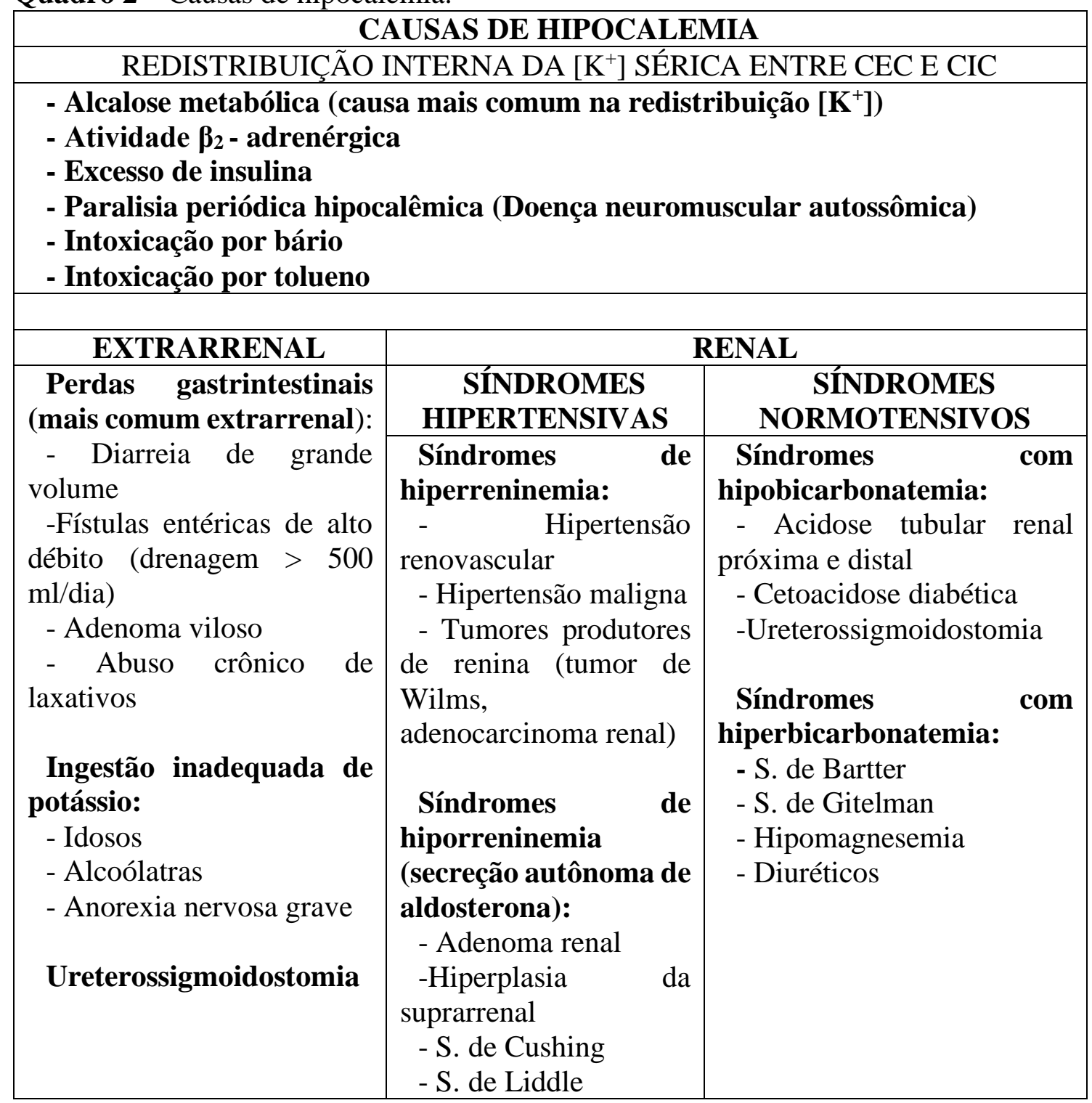

Entre outras causas de hipocalemia, pode-se citar o hipertireoidismo (aumento da síntese das bombas $\mathrm{Na}^{+} \mathrm{K}^{+}$- ATPase), intoxicação por drogas, como bário, cloroquina e verapamil que há um aumento do influxo de potássio $(1,4)$. Os estados de anabolismo (por exemplo, tratamento da anemia megaloblástica, hiperalimentação endovenosa, neoplasias hematológicas) também devem ser lembrados, pois se estima que para cada grama de tecido novo formado, necessita-se de, aproximadamente, $3 \mathrm{mmol}$ de potássio (1).

Um dado laboratorial útil na investigação é a $\left[\mathrm{K}^{+}\right]$urinária. Quando estiver inferior a 20 $\mathrm{mEq} / \mathrm{L}$ num quadro de hipopotassemia, este é um achado bastante sugestivo de perda gastrintestinal oculta (1).

Em relação às perdas renais, deve-se lembrar que até $40 \%$ dos pacientes em uso de diuréticos tiazídicos apresentam hipopotassemia $(1,4)$. O magnésio sérico deve ser dosado também, pois em situações de hipomagnesemia pode haver, por consequência, perda renal de potássio e de cloreto. Os níveis baixos de magnésio causam a diminuição da secreção do paratormônio (PTH), o que, por sua vez, pode gerar hipocalcemia. (1-5)

Outra situação que deve ser afastada é a pseudo-hipopotassemia, que ocorre quando leucócitos $>10^{5} / \mathrm{mL}$ são conservados à temperatura ambiente. Nessa situação, há uma redução na $\left[\mathrm{K}^{+}\right]$sérico, por causa do sequestro do íon pelos leucócitos. Para que isso não 
ocorra, deve-se se separar o soro imediatamente ou armazenar o sangue a $4^{\circ} \mathrm{C}$. (1).

\subsection{Quadro clínico}

Como já inferido antes, os sistemas mais atingidos são os mais dependentes e ricos em células excitáveis: nervoso e cardiovascular. Entretanto, isso não exime os demais sistemas orgânicos de prejuízos, pois, afinal, o potássio é o íon mais abundante do corpo (1-3). A seguir, as principais consequências da hipopotassemia nos principais sistemas orgânicos:

\section{a. Cardíaco}

O maior temor de todos os quadros clínicos são as alterações de condução cardíac (Quadro 3). Os achados podem ser evidenciados no eletrocardiograma (ECG) $(1,4,5)$ :

- Pode aparecer o achatamento ou inversão das ondas "T" e o surgimento das ondas "U", que podem ser notadas pelo o alongamento do intervalo QT:

Quadro 3 - Alterações da hipocalemia no eletrocardiograma.

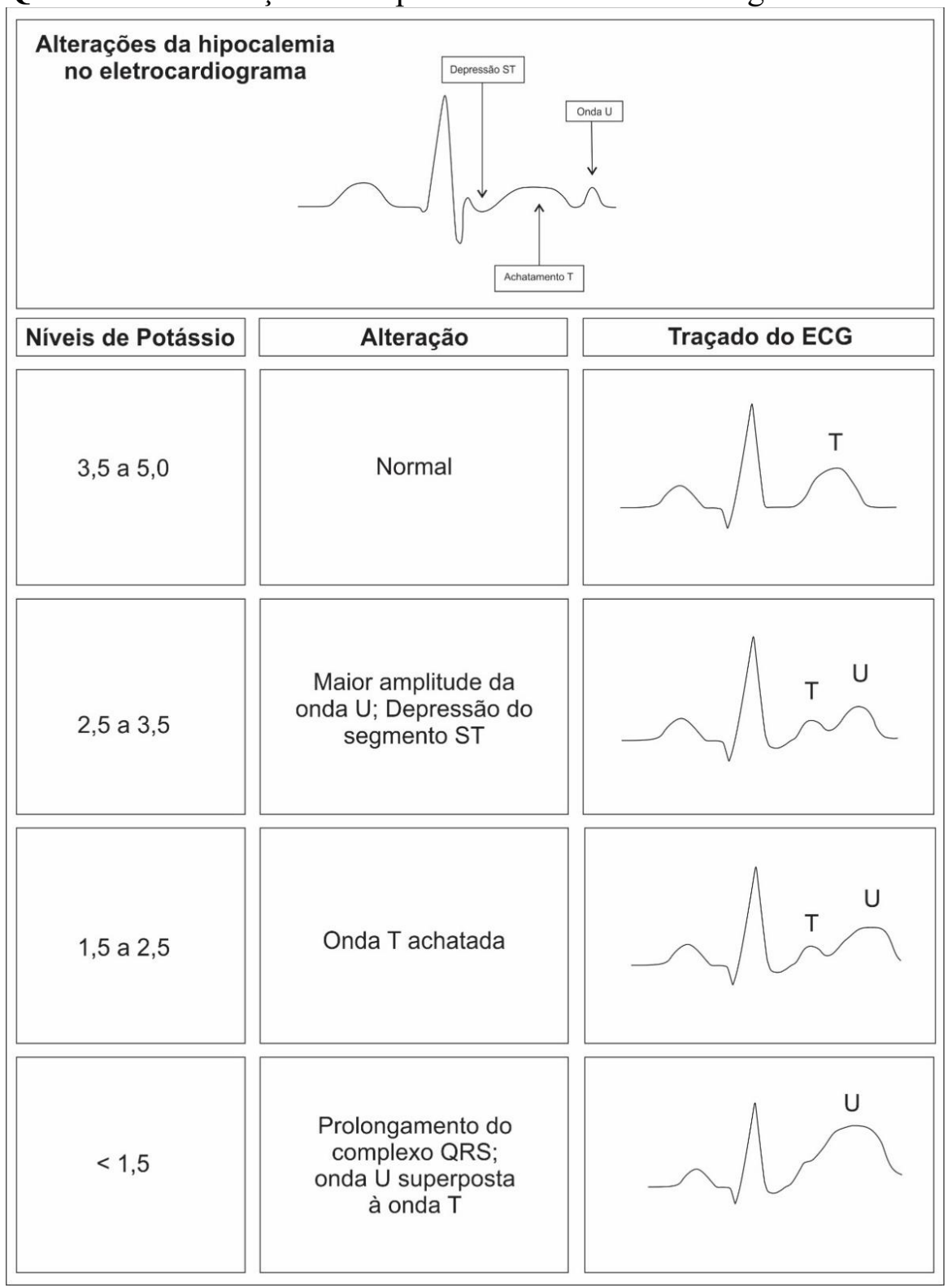


- Predisposição de focos elétricos ectópicos;

- Aumento da sensibilidade ao digital, o que pode culminar em arritmias potencialmente fatais. Esse fenômeno decorre do fato da hipopotassemia deixar mais receptores livres para a ligação do digitálico, uma vez que não há potássio suficiente para competir pelo receptor, aumentando o efeito do fármaco.

\section{b. Hemodinâmico}

A depleção de potássio causa um aumento da pressão arterial. Enquanto a sobrecarga reduz a pressão arterial, em função da natriurese. $(1,4)$

\section{c. Gastrointestinal}

Geralmente quando $\left[\mathrm{K}^{+}\right]$plasmático está inferior a $3 \mathrm{mEq} / \mathrm{L}$, o paciente pode referir constipação, podendo até ocorrer íleo paralítico. (1-4)

\section{d. Muscular}

Desde leve fraqueza até paralisia podem ser evidenciados no paciente com hipocalemia, conforme a sua intensidade. A fadiga e paralisia dos músculos respiratórios são mais frequentes quando a potassemia está abaixo de $2 \mathrm{mEq} / \mathrm{L}$, colocando a vida do paciente em risco. Pode haver rabdomiólise, seguida de necrose tubular aguda. $(1,5)$

\section{e. Renal}

Os baixos níveis de potássio podem resultar na redução da taxa de filtração glomerular (TFG), diminuindo a função renal. A mioglobinúria é outra complicação que pode acompanhar a hipocalemia, porém em casos mais severos, podendo culminar na insuficiência renal aguda. Outros efeitos renais podem ocorrer, como a incapacidade em concentrar a urina (que pode se manifestar por poliúria), o aumento da produção de amônia (que é dramático em pacientes cirróticos, podendo culminar em coma hepático) e a potencialização de drogas nefrotóxicas, caso o paciente esteja fazendo uso. $(1,5)$

\section{f. Endócrinas}

Em situações de hipopotassemia grave, há um feedback negativo intenso para a liberação da insulina, podendo inibi-la completamente. Assim, gera-se um quadro agudo de intolerância à glicose. Esse quadro complica o tratamento da diabetes mellitus, bem como pode se diagnosticar, equivocadamente, um paciente como diabético. (1)

\section{g. Sistema Nervoso Central (SNC)}

Os sinais sintomas neurológicos podem ser: irritabilidade, distúrbio de afetividade, confusão mental, hipotensão postural, letargia, apatia, alucinações e delírios. (1)

\subsection{Tratamento}

O tratamento da hipocalemia é baseado em 4 princípios $(1,4,5)$. O primeiro é a correção da causa do distúrbio, pois se remove o fator causal, quando possível, e pode corrigir o potássio sérico sem a reposição calêmica. $O$ segundo consiste na remoção de outros fatores que possam corroborar para a hipocalemia, como a terapêutica com drogas depletoras de potássio, hipomagnesemia, outros distúrbios hidroeletrolíticos e alcalose. $\mathrm{O}$ terceiro princípio se baseia na administração do potássio, quando necessário. E por último, deve-se saber determinar a urgência da correção, conforme o quadro clínico do paciente. 
Em relação aos dois últimos princípios, destacam-se as principais indicações para a reposição de potássio (Quadro 4) $(1,4,5)$ :

Quadro 4 - Principais indicações para a reposição de potássio.

- Terapêutica com digitálicos;

- Correção da cetoacidose quando a $\left[\mathrm{K}^{+}\right]$plasmático estiver baixo;

- Presença de sintomas, principalmente arritmias e hipoventilação;

- Hipocalemia severa $(<2,5 \mathrm{mEq} / \mathrm{L})$;

- Encefalopatia hepática.

Ao contrário do sódio, que predomina no CEC, é mais difícil estimar o déficit do potássio, justamente por sua maior parcela (próximo de $150 \mathrm{mEq} / \mathrm{L}$ ) encontrar-se no CIC. Em função dessa dificuldade, os estudos tentaram estimar as deficiências de potássio diretamente em razão da queda da calemia. As estimativas foram (Quadro 5) $(1,4,5)$ :

Quadro 5 - Distúrbios do K em relação a queda da calemia

- Queda de 4,0 para 3,0 mEq/L $\rightarrow$ Déficit de 200 a $400 \mathrm{mEq}$ de $\mathrm{K}^{+}$

- Queda de 4,0 para 2,0 mEq/L $\rightarrow$ Déficit de 200 a $800 \mathrm{mEq}$ de $\mathrm{K}^{+}$

O Quadro 6 seguinte mostra as soluções para reposição do potássio e as suas respectivas formulações (1):

Quadro 6 - Soluções para reposição de potássio (1)

\begin{tabular}{|c|c|c|c|}
\hline Solução/drágea & $\begin{array}{l}\text { Quantidade da } \\
\text { solução/drágea }\end{array}$ & $\begin{array}{l}\text { Quantidade de } \\
\text { potássio }\end{array}$ & Dose usual \\
\hline $\mathrm{KCl}$ a $10 \%$ & $1 \mathrm{amp}=10 \mathrm{~mL}$ & $13 \mathrm{mEq}$ & $\begin{array}{l}3 \text { amp em SF a 0,9\% } 500 \\
\text { mL (infusão lenta) }\end{array}$ \\
\hline KCl a $15 \%$ & $1 \mathrm{amp}=10 \mathrm{~mL}$ & $20 \mathrm{mEq}$ & $\begin{array}{l}2 \text { amp em SF a 0,9\% } 500 \\
\text { mL (infusão lenta) }\end{array}$ \\
\hline KCl a $19,1 \%$ & $1 \mathrm{amp}=10 \mathrm{~mL}$ & $25 \mathrm{mEq}$ & $\begin{array}{l}2 \text { amp em SF a } 0,9 \% 500 \\
\mathrm{~mL} \text { (infusão lenta - evita- } \\
\text { se o uso, quando possível) }\end{array}$ \\
\hline $\begin{array}{l}\text { KCl sol. Oral de } \\
60 \mathrm{mg} / \mathrm{mL}\end{array}$ & $\begin{array}{l}1 \text { colher de sopa } \\
=15 \mathrm{~mL}\end{array}$ & $12 \mathrm{mEq}$ & 15 a $30 \mathrm{~mL}$ até $3 x / d i a$ \\
\hline KCl em drágea & $600 \mathrm{mg}$ & $8 \mathrm{mEq}$ & 2 drágeas, $3-4 x /$ dia \\
\hline $\begin{array}{l}\mathrm{K}_{2} \mathrm{PO}_{4} 2 \\
\mathrm{mEq} / \mathrm{mL}\end{array}$ & $1 \mathrm{amp}=10 \mathrm{~mL}$ & $44 \mathrm{mEq}$ & $\begin{array}{l}1 \text { amp em SF a } 0,9 \% 500 \\
\text { mL (infusão lenta) }\end{array}$ \\
\hline
\end{tabular}

Dentre as soluções apresentadas, para a reposição em um adulto, cuja necessidade basal diária varia de 40 a $70 \mathrm{mEq} / \mathrm{dia}$, o cloreto de potássio $(\mathrm{KCl})$ é o de escolha para o manejo da hipopotassemia. Apresenta-se na forma cristalina em líquido (1 colher de chá possui de 50 a $65 \mathrm{mEq}$ de potássio), em comprimido ou cápsula de liberação lenta (8 $\mathrm{mEq} /$ cápsula). Essas apresentações devem ser analisadas sempre que a via oral é possível, uma vez que essa via é a preferencial, sempre que possível $(1,4)$. Quando está impossibilitada ou não é indicada, a via intravenosa é eleita. Geralmente se adiciona 20 a 
$40 \mathrm{mEq}$ de $\mathrm{K}^{+}$tendo de $500 \mathrm{ml}$ a 1 litro de solução salina para dissolver. Atenta-se para soluções com concentrações superiores a $60 \mathrm{mEq} / \mathrm{L}$, pois podem causar dor e esclerose do acesso venoso $(4,5)$. Para soluções mais concentradas ou com taxa de correção superior a $10 \mathrm{mEq} /$ hora, normalmente indicadas para casos mais graves, está indicado a infusão em veias mais calibrosas, como os de acessos centrais $(4,5)$.

Nos casos da necessidade de soluções muito concentradas, como no caso de um paciente que esteja congesto, necessitando de uma correção agressiva, há estudos demonstrando segurança e resolubilidade no uso pequenos volumes com altas concentrações. Abaixo, há as seguintes recomendações (Quadro 7) (6):

Quadro 7 - Reposição mais intensa de potássio.

Considerando um volume de $1000 \mathrm{~mL}$ de solução salina a $0,9 \%$, sugere-se um máximo de $60 \mathrm{mEq}$ de potássio. A quantidade de potássio a ser infundida depende da situação clínica.

Num volume de 100 a $200 \mathrm{~mL}$ de água, sugere-se $10 \mathrm{mEq}$ de potássio por acesso periférico, num período de 1 hora.

Num volume com $100 \mathrm{~mL}$ de água central, pode-se usar um máximo de $40 \mathrm{mEq}$ de potássio, por acesso central, num período de 1 hora.

De modo geral, o corpo possui mecanismos fisiológicos para responder bem a hipocalemia, tanto que a maioria dos pacientes se apresenta assintomático, não necessitando de correções tão agressivas. Entretanto, em situações específicas, essas abordagens podem ser aplicadas.

O mais comum e reproduzido na literatura é uma abordagem mais conservadora, visando uma diminuição da conversão de uma hipo para uma hipercalemia. A seguir, o Quadro 8 mostra as velocidades de correção e vias de infusão conforme o quadro clínico do paciente (4):

Quadro 8 - Esquemas para reposição de potássio.

\begin{tabular}{|c|c|c|}
\hline Quadro Clínico & Conduta & Observação \\
\hline $\begin{array}{l}\text { Assintomático ou calemia } \\
\text { entre } 3,0-3,5 \mathrm{mEq} / \mathrm{L}\end{array}$ & \multicolumn{2}{|c|}{ Aumento da ingesta de alimentos ricos em potássio } \\
\hline $\begin{array}{l}\text { Sintomas mínimos ou } \\
\text { calemia } 2,5-3,0 \mathrm{mEq} / \mathrm{L}\end{array}$ & $\begin{array}{l}\text { Reposição por via oral, } 20 \\
-80 \mathrm{mEq} / \mathrm{dia},\end{array}$ & $\begin{array}{c}\text { Caso haja intolerância por } \\
\text { via oral, a via intravenosa } \\
\text { está indicada, com a taxa } \\
\text { de correção de } 10-20 \\
\text { mEq/h. }\end{array}$ \\
\hline $\begin{array}{l}\text { Sintomas graves } \\
\text { (fraqueza musculatura } \\
\text { respiratória, arritmias) } \\
\text { ou calemia }<2,5 \mathrm{mEq} / \mathrm{L}\end{array}$ & $\begin{array}{c}\text { Reposição por via } \\
\text { intravenosa, em velocidade } \\
\text { de correção de } 10-20 \\
\mathrm{mEq} / \mathrm{h}\end{array}$ & $\begin{array}{c}\text { Lembrar de avaliar a } \\
\text { necessidade de reposição } \\
\text { do magnésio. }\end{array}$ \\
\hline $\begin{array}{c}\text { Presença de Fibrilação } \\
\text { Ventricular ou } \\
\text { Taquicardia Ventricular }\end{array}$ & $\begin{array}{l}\text { Fazer reposição via } \\
\text { intravenosa, de } 20 \mathrm{mEq} \\
\text { em 3-10 minutos, seguida } \\
\text { de } \\
\text { reposição em velocidade de } \\
\text { correção de } 10-20 \mathrm{mEq} / \mathrm{h} \text {. }\end{array}$ & $\begin{array}{l}\text { Realizar mensurações do } \\
\text { potássio após cada } \\
\text { correção, para evitar a } \\
\text { hipercalemia. }\end{array}$ \\
\hline
\end{tabular}




\subsection{Exercício}

Paciente masculino de 69 anos, diabético e sem acompanhamento médico, fumante (39 anos-maço), hipertenso e com diagnóstico prévio de insuficiência cardíaca congestiva, apresenta-se no pronto socorro com intensa fraqueza e dispneia que começou há 4 horas e piora progressiva. Refere sentir que o coração "pula e para no peito". Faz uso de hidroclorotiazida e captopril. Ao exame físico, há estertores crepitantes em ambos terços inferiores dos campos pulmonares, edema com sinal do cacifo em ambos os membros inferiores, sem sinais flogísticos. Os exames laboratoriais revelam a $\left[\mathrm{K}^{+}\right]=2,3 \mathrm{mEq} / \mathrm{L}$. O ECG revela ritmo irregular, achatamento da onda T e o aparecimento da onda U. Qual o diagnóstico e conduta?

Resposta: Com a calemia abaixo de $2,5 \mathrm{mEq} / \mathrm{L}$, a hipopotassemia desse paciente é considerada como severa e sintomática, uma vez que ele relate sintomas neuromuscular e cardíaco (fraqueza e palpitações, respectivamente). Dessa forma, este é um paciente grave, devendo ter a sua reposição de potássio mais agressiva $(20 \mathrm{mEq} / \mathrm{hora})$, por via intravenosa, até atingir $3.0 \mathrm{mEq} / \mathrm{L}$ de potassemia. A partir disso, inicia-se a reposição por via oral, de 20 a $80 \mathrm{mEq} / \mathrm{dia}$, até atingir a calemia alvo de $4,0 \mathrm{mEq} / \mathrm{L}$, que é o desejado para paciente com insuficiência cardíaca ou infarto recente. Lembrando que se deve ter cuidado com a infusão de potássio, pois se houver um excesso na infusão, o risco de arritmias malignas permanece. Outro cuidado, é com a volemia do paciente, pois este demonstra uma descompensação de sua insuficiência cardíaca. Por isso se recomenda infundir de pouco em pouco, e caso a potassemia desejada não seja atingida, repete-se a prescrição inicial até atingi-la.

Supõe-se que o paciente não se apresenta descompensado de sua insuficiência cardíaca, de modo que seja possível a infusão plena de volume. Sob essas condições, seria possível preparar uma solução de 1 litro de soro fisiológico (SF) a 0,9\%, com $39 \mathrm{mEq}$ de potássio. Para isso, pega-se um litro de SF $0,9 \%$, desprezando $30 \mathrm{~mL}$, e adicionando 3 ampolas de $10 \mathrm{~mL}$ de $\mathrm{KCl} 10 \%$ (totalizando $30 \mathrm{ml}$ com $39 \mathrm{mEq}$ ). Com essa solução, de concentração próxima de $39 \mathrm{mEq} / \mathrm{L}$, pode-se infundir $500 \mathrm{~mL}$ no paciente, em 1 hora, (aproximadamente $20 \mathrm{mEq} /$ hora) com monitorização cardíaca contínua, devendo-se realizar nova avaliação do paciente posteriormente, do ponto de vista eletrolítico e volêmico.

Entretanto, o paciente em questão não possui condições para receber volume, pois já demonstra sinais de congestão franca. Assim, é preferível a infusão de soluções com altas concentrações de potássio, em baixos volumes. Uma opção viável é a infusão de $100 \mathrm{~mL}$ de água, em 1 hora, por via central (de preferência a mais distante do coração) com no máximo $40 \mathrm{mEq}$ de potássio. A monitorização eletrocardiográfica contínua e eletrolítica (incluindo o magnésio) deve ser rigorosa, devido ao risco de arritmias e conversão para hipercalemia.

Ainda, no manejo desse paciente, o diurético tiazídico deve ser suspenso ou trocado por um poupador de potássio, pois é um dos principais causadores e intensificadores da hipopotassemia (Quadro 9). Outras causas também devem ser investigadas. 
Quadro 9- Pontos importantes na hipopotassemia.

- Importante frisar que se os pacientes estiverem fazendo uso crônico de diuréticos, devem trocar para os diuréticos poupadores de potássio $(1,4,5)$;

- Os pacientes devem ter o seu potássio monitorizado a cada 3 a 6 horas e, os graves, devem ter monitoração cardíaca contínua, principalmente quando a infusão for superior a $10 \mathrm{mEq}$ por hora (1);

- Paciente com insuficiência cardíaca ou infarto recente são mais propensos a terem sintomas na hipocalemia. Dessa forma, a calemia alvo desses pacientes é 4,0 a 5,5 mEq/L (4,5).

- Caso não haja melhora da calemia do paciente após a reposição de potássio, (seja leve,moderado ou grave), deve-se suspeitar de depleção de magnésio. Caso se confirme essa suspeita, repor com 2 a 3 gramas de sulfato de magnésio por dia (1).

- Nos casos que houver indicação de infusão intravenosa, prefere-se os acessos mais distantes do coração, como os femorais, visando evitar arritmias $(1,4,5)$.

\section{Hipercalemia}

\subsection{Definição}

A hipercalemia é diagnosticada quando o potássio sérico do paciente é superior a 5,5 $\mathrm{mEq} / \mathrm{L}$. Estima-se que $10 \%$ dos pacientes hospitalizados tenham esse distúrbio hidroeletrolítico, que é considerado grave, pois é o que mais se associa às arritmias ventriculares e paradas cardiorrespiratórias, podendo ter uma mortalidade que beira os $50 \%$, caso o tratamento não seja prontamente realizado $(1,5,7,8)$.

Felizmente, há mecanismos fisiológicos que nos protegem do estado de potássio em demasia. Os principais são a adaptação celular e, fundamentalmente, a excreção urinária (1-3).

Quando houver o diagnóstico de hiperpotassemia, deve-se excluir a pseudohiperpotassemia (Quadro 10), que ocorre nas seguintes situações (1):

Quadro 10 - Pseudohiperpotassemia.

- Leucocitose $>100.000 / \mathrm{mm}^{3}$

- Plaquetose $>400.000 / \mathrm{mm}^{3}$

- Hemólise

- Coleta inadequada (garroteamento excessivo, trauma do local, demora na dosagem) 


\subsection{Etiologia}

Considerando que a maior parte do potássio está no CIC, pode-se concluir que quando, por algum motivo, esse potássio passa do CIC para o CEC, e não há adequada excreção renal, o paciente desenvolve hipercalemia. Portanto, os dois grandes braços etiológicos do potássio em excesso no CEC são a redistribuição calêmica e a eliminação renal de potássio reduzida (Quadro 11) (1,5,7,8). Dessa forma, será apresentado as principais etiologias de cada braço, no quadro 3 (1).

Em relação às drogas, podem causar a hipocalemia por meio de 3 principais mecanismos $(1,5)$ :

a. Aumento do aporte de potássio:

- Na infusão de 1.000.000 de unidades de penicilina G potássica, há 1,7 mEq do íon. A alimentação suplementar também pode elevar a calemia do paciente.

b. Troca de compartimento:

- Beta-bloqueadores diminuem a liberação de renina mediada pelas catecolaminas e, principalmente, reduzem a função da bomba de sódio-potássio-ATPase e o recrutamento de potássio para o meio intracelular.

- Digoxina inibe a bomba de $\mathrm{Na}^{+} \mathrm{K}^{+}$- ATPase e a redução da excreção renal de potássio.

- Aminoácidos naturais, como a arginina, ou sintéticos, como o ácido épsilonaminocaproico, podem gerar hipercalemia, quando infundidos, pois para entrarem na célula, estes são trocados por potássio na membrana celular.

c. Redução da excreção renal:

* Anti-inflamatórios não esteroidais (AINES) inibem a atividade das prostaglandinas PGE2 e PGI2, sendo que estas, são responsáveis pela estimulação da síntese de renina e, consequentemente, da liberação de aldosterona. Sendo assim, os AINES podem gerar um quadro de hipoaldosteronismo e hiporeninêmico secundários, culminando numa hipercalemia.

* Inibidores da enzima conversora da angiotensina (IECA) e os bloqueadores do receptor angiotensina II (BRA) também inibem a aldosterona. Portanto, também podem gerar hipercalemia.

* Ciclosporina e tacrolimus causam disfunção celular pelo hipoaldosteronismo secundário, o que também culmina num aumento da potassemia.

* Heparina tem um mecanismo subjacente que inibe a produção adrenal de aldosterona. 
Quadro 11 - Causas de hiperpotassemia.

\begin{tabular}{|c|c|c|}
\hline & REDISTRIBUI & 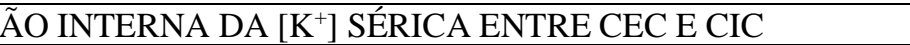 \\
\hline & Acidoses & $\begin{array}{l}\text { Em situações de acidose, o sistema tampão intracelular faz com } \\
\text { que o hidrogênio em excesso seja trocado por um potássio, } \\
\text { gerando uma hiperpotassemia relativa. Mais evidente em } \\
\text { acidoses metabólicas, enquanto nas respiratórias, se a } \\
\text { hipercalemia ocorrer, será mínima. } \\
\text { Estima-se que para cada redução de } 0,1 \text { no pH, há uma elevação } \\
\text { de } 0,7 \mathrm{mEq} / \mathrm{L} \text { na }\left[\mathrm{K}^{+}\right] \text {. }\end{array}$ \\
\hline & Deficiência de insulina & 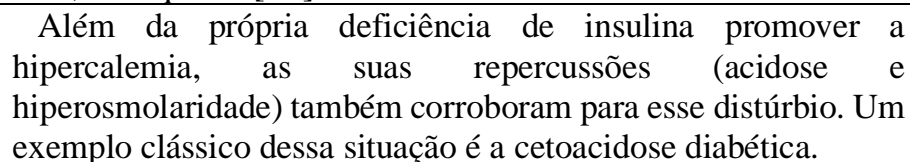 \\
\hline & Hemólises & $\begin{array}{l}\text { Com a ruptura celular das hemácias, o potássio intracelular } \\
\text { extravasa para o CEC, de modo a elevar a potassemia. Esse } \\
\text { quadro pode ser transitório, muitas vezes sem repercussões, } \\
\text { porém quando associado uma insuficiência renal aguda, o quadro } \\
\text { clínico se torna mais dramático. }\end{array}$ \\
\hline & Soluções hipertônicas & $\begin{array}{l}\text { Essas soluções aumentam a tonicidade do CEC, havendo então } \\
\text { uma contração ou até necrose celular, dependendo da rapidez do } \\
\text { aumento da tonicidade, com a saída do potássio intracelular. }\end{array}$ \\
\hline & Destruição celular & $\begin{array}{l}\text { Como já dito, a concentração do potássio intracelular pode ser } \\
\text { até } 40 \text { vezes superior no meio intracelular quando comparado ao } \\
\text { meio extracelular. Portanto, quando ocorre lesões celulares } \\
\text { maciças, todo esse potássio extravasa para o CEC, elevando a } \\
\text { calemia do indivíduo. Essas situações se agravam no caso de } \\
\text { insuficiência renal aguda (IRA). Pode ocorrer, em situações de } \\
\text { necrose tecidual aguda, rabdomiólise, uso de fármacos } \\
\text { citotóxicos e trauma. }\end{array}$ \\
\hline II & Fármacos & $\begin{array}{l}\text { Uma vez que a atividade } \beta_{2} \text {-adrenérgica promova o ingresso de } \\
\text { potássio no meio intracelular, os fármacos que inibam esse } \\
\text { mecanismo, podem aumentar a quantidade de potássio sérico. } \\
\text { Como por exemplo, os tão usados } \beta \text {-bloqueadores. } \\
\text { Medicamentos que atuam na despolarização das membranas } \\
\text { também podem contribuir para a hipercalemias, como é o caso } \\
\text { dos digitálicos. }\end{array}$ \\
\hline & Hipoaldosteronismo & $\begin{array}{l}\text { Uma vez que a aldosterona é a principal substância envolvida } \\
\text { na secreção renal do potássio, no túbulo coletor ao trocá-lo pelo } \\
\text { sódio, se houver uma diminuição da sua atividade, o potássio } \\
\text { acaba sendo retido no organismo do indivíduo. Portanto, drogas } \\
\text { como a espironolactona (antagonista do receptor da aldosterona) } \\
\text { podem resultar numa hiperpotassemia. }\end{array}$ \\
\hline & IRA & $\begin{array}{l}\text { A excreção de potássio depende da TFG. Quando a TFG } \\
\text { diminui abruptamente, os níveis de potássio se elevam, pois há } \\
\text { lesões tubulares que diminuem a secreção do potássio. Quando a } \\
\text { IRA está associada às outras condições que podem gerar um } \\
\text { aumento da calemia, há um aumento do risco de hipercalemia } \\
\text { graves. }\end{array}$ \\
\hline & $\begin{array}{l}\text { - Insuficiência renal } \\
\text { crônica (IRC) }\end{array}$ & $\begin{array}{l}\text { Nos quadros de IRC, ocorre uma adaptação dos néfrons sadios } \\
\text { remanescentes, os quais acabam compensando a secreção dos } \\
\text { outros, que já não estão funcionais. Esse prejuízo funcional se } \\
\text { deve ao processo de hialinização e fibrose dos glomérulos, } \\
\text { interstício e túbulos renais. } \\
\text { Em razão dessa adaptação, os níveis de potássio tendem a subir } \\
\text { quando a TFG estiver muito diminuída ( }<10 \mathrm{~mL} / \text { minuto). }\end{array}$ \\
\hline
\end{tabular}


Estudos mostram que $75 \%$ dos pacientes com hiperpotassemia severa se apresentavam com insuficiência renal. E que $67 \%$ estavam em uso de algum fármaco que favorecia o aumento da potassemia (1).

Alguns dados da investigação etiológica contribuem para a detecção da etiologia da hipercalemia. A avaliação da TFG é de fundamental importância $(1,5,8)$ :

Quadro 12- TFG e possíveis diagnósticos associados à hipercalemia.

\begin{tabular}{|c|c|}
\hline TFG & Possíveis diagnósticos \\
\hline $\begin{array}{c}\text { TFG }<10 \mathrm{~mL} / \text { minuto } \\
\text { Ou } \\
\text { Creatinina aumentada }\end{array}$ & Sugestivo de IRA, IRC ou doenças renais. \\
\hline TFG $>20 \mathrm{~mL} / \mathrm{minuto}$ & $\begin{array}{l}\text { A investigação passa a depender dos níveis sérico de } \\
\text { aldosterona e renina: } \\
\text { Aldosterona aumentada ou normal } \rightarrow \text { O esperado seria } \\
\text { hipocalemia, entretanto quando há hipercalemia, é sugestivo } \\
\text { que esta decorra do efeito de algum fármaco como } \\
\text { espironolactona, diuréticos de ação distal (Amilorida) ou } \\
\text { alterações tubulares primárias. } \\
\text { Aldosterona diminuída com renina normal ou elevada } \rightarrow \\
\text { Sugestivo de doença de Addison } \\
\text { Aldosterona diminuída com renina baixa } \rightarrow \text { Sugestivo de } \\
\text { hipoaldosteronismo hiporreninêmico }\end{array}$ \\
\hline
\end{tabular}

\subsection{Classificação (Figura 2)}
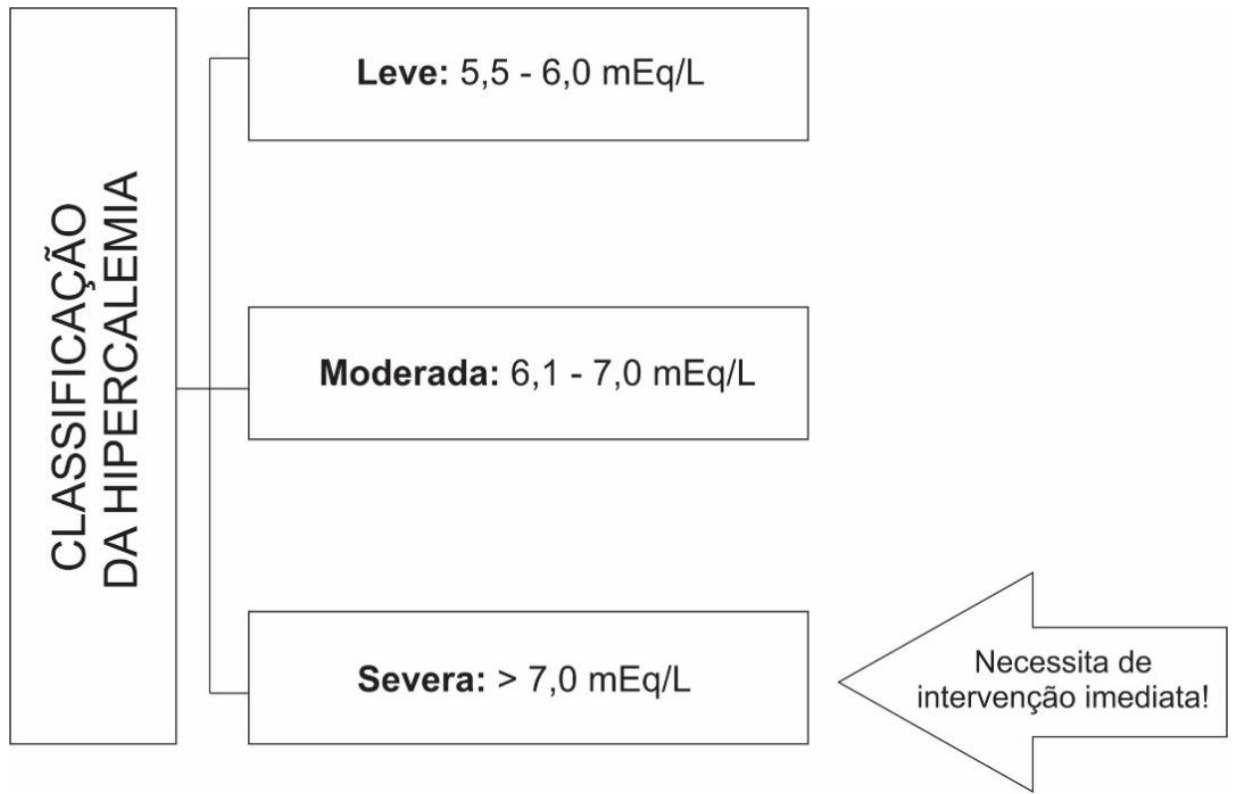

Figura 2 - Causas da hipercalemia. 


\subsection{Quadro clínico}

O quadro clínico não possui uma relação direta com os níveis de potássio sérico do paciente (Quadro 13), pois, por exemplo, se um paciente com IRC tiver níveis elevados de potássio não apresentará a mesma sintomatologia exuberante que um paciente jovem sem comorbidades (1). Portanto, assim, como em outros distúrbios hidroeletrolíticos, o paciente pode se mostrar desde assintomático até em parada cardiorrespiratória $(4,5,7,8)$.

As alterações da hipercalemia podem ser divididas em duas categorias principais:

a. Alterações musculares

* Fraqueza muscular, astenia, parestesia, hiporreflexia, paralisia flácida simétrica, começando nas mãos e nos pés e se estendo proximalmente.

* Alterações cardíacas

* Geralmente ocorre quando a $\left[\mathrm{K}^{+}\right]$sérico está acima de 7,0 mEq/L. Com a elevação do potássio no CEC, as membranas ficam despolarizadas, diminuindo a velocidade de condução cardíaca (bloqueio) e estimulando o automatismo cardíaco. Sinais e sintomas de instabilidade hemodinâmica podem estar presentes.

* O ECG deve ser solicitado sempre que houver hipótese diagnóstica de hipercalemia. Entretanto, a ausência de alterações eletrocardiográficas não exclui o diagnóstico. Um estudo revelou que apenas $55 \%$ dos pacientes com $\left[\mathrm{K}^{+}\right]$superior a $6,8 \mathrm{mEq} / \mathrm{L}$ possuíam alguma alteração eletrocardiográfica sugestiva de hipercalemia. O diagnóstico de hiperpotassemia por meio do ECG tem baixa sensibilidade (35-43\%) e alta especificidade (85-86\%). A principais alterações eletrocardiográficas são mostradas no quadro a seguir $(1,4,7,8)$ :

Quadro 13 - Manifestações da hipercalemia no ECG (1).

\begin{tabular}{|l|l|}
\hline Nível sérico de potássio & Alteração eletrocardiográfica \\
\hline Hipercalemia leve & Onda T apiculada ("em tenda") \\
\hline Hipercalemia moderada & Intervalo PR prolongado \\
& Achatamento da onda P \\
& Alargamento do QRS \\
\hline Hipercalemia severa & Ausência de onda P \\
& Bloqueio intraventricular (fascicular, \\
& bloqueio de ramo) \\
& Onda sinusoidal \\
& Fibrilação ventricular, assistolia \\
\hline
\end{tabular}

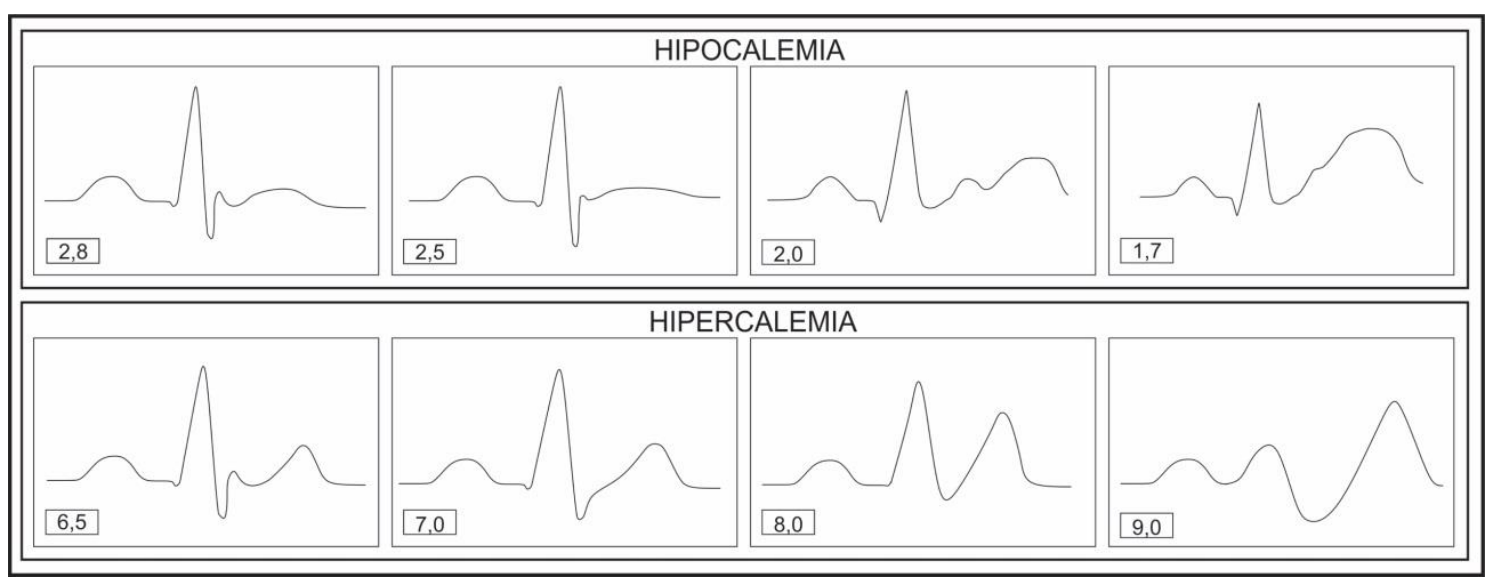

Figura 3 - Comparação entre hipocalemia e hipercalemia.

Após a análise da Figura 3, podemos concluir que a onda T aumenta quando o potássio 
aumenta. E o oposto também é verdadeiro: quando o potássio diminui, a onda T sofre um achatamento. Portanto, a distinção entre os dois distúrbios por meio do ECG apresenta boa especificidade. Porém, pelo fato dessas alterações nem sempre ocorrerem, a sensibilidade do diagnóstico é baixa, o que justifica a solicitação da dosagem do potássio sérico para se fazer o diagnóstico definitivo, independentemente do ECG.

\subsection{Tratamento}

Uma vez que haja potássio em demasia no CEC, impedindo adequada despolarização das membranas celulares (principalmente nos tecidos neuromusculares), o tratamento visa justamente remover o excesso desse íon. Para esse fim, dispomos de duas vias: carrear o potássio para o meio intracelular e/ou eliminar o $\mathrm{K}^{+}$excedente do organismo $(1,4,5,7,8)$. Portanto, para atingir a redução do potássio sérico, aplica-se as medidas gerais e, conforme a história clínica do paciente, administra-se outras terapêuticas indicadas.

As medidas gerais, que são indicadas para qualquer paciente em hipercalemia, são (1):

1) Dieta pobre em potássio;

2) Interrupção do uso de drogas que podem elevar o potássio: IECA, betabloqueadores, BRA, antagonistas da aldosterona.

As demais modalidades terapêuticas dependem dos seguintes aspectos clínicos do paciente:

- Presença ou ausência de alterações no ECG decorrentes da hipercalemia

- Velocidade das alterações nos níveis séricos do potássio, para determinar se é aguda ou crônica.

- Análise das doenças ou condições desencadeantes ou contribuintes para o distúrbio calêmico

Após considerar a clínica do paciente, disponibiliza-se os seguintes medicamentos, conforme a indicação (Quadro 14 a 21) $(1,4,8)$ :

Quadro 14 - Terapêutica com cálcio (1).

\begin{tabular}{|c|c|}
\hline & 1) CÁLCIO \\
\hline Indicação & $\begin{array}{l}\text { Na presença de qualquer alteração no ECG (alargamento do } \\
\text { QRS, ou perda da onda P, ou onda T apiculada) ou sintomas } \\
\text { exuberantes de fraqueza muscular e fadiga respiratória, a } \\
\text { primeira medida deve ser a administração de cálcio. }\end{array}$ \\
\hline $\begin{array}{l}\text { Mecanismo de } \\
\text { ação }\end{array}$ & $\begin{array}{l}\text { Antagoniza os efeitos da hipercalemia na membrana celular do } \\
\text { miócito, por mecanismos não bem compreendidos, atuando no } \\
\text { sistema de condução cardíaco. }\end{array}$ \\
\hline Início de ação & 1 a 5 minutos \\
\hline Duração da ação & a 60 minutos \\
\hline $\begin{array}{l}\text { Formulações } \\
\text { posologia }\end{array}$ & $\begin{array}{l}\text { Gluconato de cálcio a } 10 \% \text { ( } 1 \text { ampola com } 10 \text { mL possui } 1.000 \\
\text { mg): infusão em } 2 \text { a } 10 \text { minutos com monitoração cardíaca } \\
\text { contínua. A dose pode ser repetida de } 5 \text { em } 5 \text { minutos, caso a } \\
\text { alteração do ECG persista. } \\
\text { Não deve ser administrado em soluções contendo bicarbonato, } \\
\text { pela precipitação de carbonato de cálcio. } \\
\text { Nos pacientes que estiverem em uso de digoxina, a infusão deve } \\
\text { ser mais cuidadosa. Infusão de } 20 \text { a } 30 \text { minutos, visando evitar a } \\
\text { hipercalcemia; } 5 \text { a } 10 \mathrm{~mL} \text { de Cloreto de cálcio a } 10 \% \text { ( } 500 \mathrm{mg} \text { a } \\
1.000 \mathrm{mg} \text { ): infusão em } 2 \text { a } 10 \text { minutos com monitoração cardíaca }\end{array}$ \\
\hline
\end{tabular}




\begin{tabular}{|l|l|}
\hline $\begin{array}{l}\text { contínua. O cloreto possui aproximadamente, } 3 \text { vezes mais cálcio } \\
(6,8 \mathrm{mEq} / 10 \mathrm{~mL}) \text { que o gluconato }(2.2 \mathrm{mEq} / \mathrm{L}) \text { e, por isso, deve }\end{array}$ \\
$\begin{array}{l}\text { ser infundido por acesso venoso central. Prefere-se usá-lo em } \\
\text { pacientes com instabilidade hemodinâmica ou insuficiência } \\
\text { hepática. }\end{array}$
\end{tabular}

Quadro 15 - Terapêutica com solução polarizante (1).

\begin{tabular}{|l|l|}
\hline \multicolumn{2}{|c|}{ 2) GLICOINSULINOTERAPIA (SOLUÇÃO POLARIZANTE) } \\
\hline Indicação & Hipercalemia aguda \\
\hline Mecanismo de ação & $\begin{array}{l}\text { Deslocamento do potássio para o CIC, principalmente nos } \\
\text { hepatócitos e miócitos, aparentemente pelo aumento da } \\
\text { atividade da bomba de } \mathrm{Na}^{+} \mathrm{K}^{+} \text {- ATPase. Promove queda de } \\
0,5 \text { a } 1,5 \mathrm{mEq} / \mathrm{L} \text { na concentração plasmática de potássio. }\end{array}$ \\
\hline Início de ação & 15 minutos, tendo o pico de ação em 60 minutos \\
\hline Duração da ação & 4 a 6 horas \\
\hline $\begin{array}{l}\text { Formulações } \\
\text { posologia }\end{array}$ & $\begin{array}{l}1 \text { unidade de insulina regular para cada } 5 \text { gramas de } \\
\text { glicose. Na prática: SG a } 10 \% \text { 500 Ml + Insulina R, 10 } \\
\text { unidades intravenosa, a cada } 4 \text { horas. Geralmente ocorre } \\
\text { queda de } 0,5 \text { a } 1,5 \mathrm{mEq} / \mathrm{L} \text { no potássio sérico. }\end{array}$ \\
\hline
\end{tabular}

Quadro 16 - Terapêutica com bicarbonato e sódio (1).

\begin{tabular}{|c|c|}
\hline \multicolumn{2}{|r|}{ 3) BICARBONATO DE SÓDIO } \\
\hline Indicação & Hipercalemia com acidose metabólica severa \\
\hline Mecanismo de ação & Deslocamento do potássio para o CIC \\
\hline Início de ação & 30 a 60 minutos \\
\hline Duração da ação & 1 a 2 horas \\
\hline Cálculo da dose & Déficit de Base $(D B)=0,3 \times$ Base Excess $\times$ Peso \\
\hline $\begin{array}{l}\text { Formulações } \\
\text { posologia }\end{array}$ & $\begin{array}{l}\text { O bicarbonato de sódio a } 8,4 \%(1 \mathrm{mEq} / \mathrm{mL}), 50 \mathrm{~mL} \text {, em } 5 \\
\text { minutos. Pode ser repetido em } 30 \text { minutos se necessário. } \\
\text { Em pacientes renais crônicos, pode ser utilizada dose maior, } \\
\text { de acordo com a acidose que o paciente apresentar. } \\
\text { Outra forma, é calcular o déficit de base e repor } 1 / 3 \text { da } \\
\text { dose. Em seguida, calcula-se novamente o DB. }\end{array}$ \\
\hline Limitações & $\begin{array}{l}\text { Pouca resposta em pacientes sem acidose metabólica } \\
\text { Sobrecarga de volume }\end{array}$ \\
\hline
\end{tabular}

Quadro 17 - Beta 2 agonistas (1).

\begin{tabular}{|l|l|}
\hline \multicolumn{2}{|l|}{ 4) BETA 2 - AGONISTAS } \\
\hline Indicação & Hipercalemia aguda \\
\hline Mecanismo de ação & $\begin{array}{l}\text { Deslocamento do potássio para o CIC, principalmente nos } \\
\text { hepatócitos e miócitos, aparentemente pelo aumento da atividade } \\
\text { da bomba de } \mathrm{Na}^{+} \mathrm{K}^{+} \text {- ATPase. Promove queda de } 0,5 \text { a } 1,5 \mathrm{mEq} / \mathrm{L} \\
\text { na concentração plasmática de potássio. Possui efeito sinérgico } \\
\text { com a infusão de glicoinsulina. }\end{array}$ \\
\hline Início de ação & 20 a 30 minutos \\
\hline Duração da ação & 2 a 4 horas \\
\hline Formulações e posologia & $\begin{array}{l}\text { Nebulização com albuterol } 10 \text { a } 20 \mathrm{mg} \text { em } 5 \mathrm{~mL} \text { de SF por } 10 \\
\text { minutos } \\
\text { Outra opção é fenoterol, } 10 \text { gotas por via inalatória diluídas em } 3 \\
\text { a } 5 \text { mL de SF a } 0,9 \%\end{array}$ \\
\hline
\end{tabular}




\begin{tabular}{|l|l|}
\hline & $\begin{array}{l}\text { Ou, ainda, salbutamol }(10 \text { a } 20 \mathrm{mg} \text { diluídos em } 4 \mathrm{~mL} \text { de solução } \\
\text { salina na form ade inalação por } 10 \text { minutos } \\
\text { O albuterol e o fenoterol podem ser usados em associação com a } \\
\text { solução polarizante nos pacientes com IRC, para maximizar a } \\
\text { redução do potássio sérico }\end{array}$ \\
\hline Limitações & $\begin{array}{l}\text { Ausência de respostas em } 20 \text { a } 33 \% \text { dos pacientes } \\
\text { Não utilizar em pacientes coronariopatas ou com arritmias }\end{array}$ \\
\hline
\end{tabular}

Quadro 18 - Terapêutica com diuréticos de alça (1).

\begin{tabular}{|l|l|}
\hline \multicolumn{3}{|c|}{ 5) DIURÉTICOS DE ALÇA } \\
\hline Indicação & Hipercalemia aguda ou crônica (principalmente) \\
\hline Mecanismo de ação & Aumenta a excreção renal de potássio \\
\hline Início de ação & 15 minutos \\
\hline Duração da ação & 4 a 6 horas \\
\hline $\begin{array}{c}\text { Formulações } \\
\text { posologia }\end{array}$ & $\begin{array}{l}\text { Furosemida } 40 \text { a } 80 \quad \mathrm{mg}, \text { intravenoso, em bolus, } \\
\text { preferencialmente }\end{array}$ \\
\hline Limitações & Pacientes com IRC responde mal a essa terapêutica \\
\hline
\end{tabular}

Quadro 19 - Terapêutica com resina de troca (1).

\begin{tabular}{|l|l|}
\hline \multicolumn{2}{|l|}{ 6) RESINA DE TROCA } \\
\hline Indicação & Hipercalemia aguda ou crônica (principalmente) \\
\hline Mecanismo de ação & $\begin{array}{l}\text { Troca cálcio por potássio no trato gastrintestinal, } \\
\text { promovendo sua eliminação fecal, ao impedir a sua } \\
\text { absorção }\end{array}$ \\
\hline Início de ação & 1 a 2 horas \\
\hline Duração da ação & 4 a 6 horas \\
\hline $\begin{array}{l}\text { Formulações } \\
\text { posologia }\end{array}$ & $\begin{array}{l}\text { Sorcal (poliestirenossulfonato de cálcio contendo 3,3 mEq } \\
\text { de cálcio por grama) } 30 \mathrm{mg} \text {, de } 8 \text { em } 8 \text { horas a } 4 \text { em } 4 \text { horas, } \\
\text { via oral; ou 50 gramas da solução adicionados a 150 mL de } \\
\text { água, por via retal, por no mínimo 30 a } 60 \text { minutos, caso } \\
\text { haja vômitos (usado como enema de retenção). Cada grama } \\
\text { de resina se liga a } 1 \text { mEq de potássio e libera 1 a } 2 \mathrm{mEq} \mathrm{de} \\
\text { sódio. Cada enema pode reduzir o potássio sérico em 0,5 a } \\
1,0 \text { mEq/L e pode ser repetido a cada } 2 \text { a 4 horas }\end{array}$ \\
\hline Limitações & $\begin{array}{l}\text { Pode causar constipação intestinal e necrose intestinal, } \\
\text { quando administrado pela via retal. Num pequeno grupo de } \\
\text { pacientes, pode causar hipomagnesemia. }\end{array}$ \\
\hline
\end{tabular}

Quadro 20 - Terapêutica com diálise (1).

\begin{tabular}{|l|l|}
\hline \multicolumn{2}{|c|}{ 1) DIÁLISE } \\
\hline Indicação & $\begin{array}{l}\text { Hipercalemia grave, persistente ou recorrente, refratária às } \\
\text { medidas citadas anteriormente, principalmente na presença } \\
\text { de insuficiência renal e nas condições clínicas com } \\
\text { liberação de grandes quantidades de potássio (rabdomiólise, } \\
\text { hemólise) }\end{array}$ \\
\hline Início de ação & Imediata \\
\hline Duração da ação & Até o término da diálise \\
\hline $\begin{array}{l}\text { Vantagem da } \\
\text { hemodiálise em relação } \\
\text { à diálise peritoneal }\end{array}$ & $\begin{array}{l}\text { É preferível pela velocidade de remoção do potássio, que } \\
\text { varia de } 1,2 \text { a } 1,5 \mathrm{mEq} / \text { hora. }\end{array}$ \\
\hline
\end{tabular}


Quadro 21 - Tratamento de hiperpotassemia (1).

\begin{tabular}{|l|l|}
\hline Estabilizador de membranas & Cálcio \\
\hline Troca de compartimento & $\begin{array}{l}\text { Insulina + glicose } \\
\text { Bicarbonato de sódio } \\
\text { Beta 2 -adrenérgico }\end{array}$ \\
\hline Remoção do potássio & $\begin{array}{l}\text { Diuréticos de alça/tiazídicos } \\
\text { Resina de troca } \\
\text { Diálise }\end{array}$ \\
\hline
\end{tabular}

\subsection{Exercício}

Paciente de 68 anos é trazido para emergência por seus familiares, apresentando-se com queixa de fraqueza muscular generalizada e incapacidade para deambulação. Os acompanhantes contam que é um hipertenso mal controlado e doente renal crônico. Paciente não faz acompanhamento com o nefrologista. Faz uso de captopril $25 \mathrm{mg}$ regularmente. Os exames laboratoriais são solicitados e evidenciam o seguinte: TFG $=13,2 \mathrm{ml} / \mathrm{min} ;$ ureia $=187 \mathrm{mg} / \mathrm{dL} ;$ potássio $=7,5 \mathrm{mEq} / \mathrm{L} ; \mathrm{pH}=7,4 ;$ bicarbonato $=22$ $\mathrm{mEq} / \mathrm{L}$. O ECG revela o achatamento da onda P e a apiculação da onda T. Qual o diagnóstico e a conduta?

Resposta: Com uma calemia superior a 7,0 mEq/L, diagnostica-se o paciente em hipercalemia severa. Os outros dados laboratoriais, não demonstram nenhum distúrbio do equilíbrio acidobásico associado. Nessa situação, é mandatória a solicitação de um ECG, que revela onda $\mathrm{T}$ apiculada $\mathrm{e}$ onda $\mathrm{P}$ achatada. Frente a essas alterações eletrocardiográficas, deve-se iniciar imediatamente gluconato de cálcio a 10\%, pois, em virtude do alto risco de arritmias ventriculares, este fármaco possui o início de ação mais rápido, quando comparado com os outros medicamentos, e possui a capacidade de estabilizar a membrana celular. Ainda, o paciente deve estar em monitoração cardíaca contínua. Caso as alterações do ECG persistam por mais 5 minutos, após a infusão do gluconato, deve-se repetir a dose. Se não houver melhora no padrão do ECG e/ou o paciente piorar clinicamente, deve-se associar outros fármacos como beta 2-agonistas ou solução polarizante. Se as alterações do ECG forem sanadas, ainda se deve mobilizar o potássio em excesso no CEC. Para isso se usa a solução polarizante (preferível) ou os beta2-adrenérgicos ou os dois fármacos associados. O bicarbonato de sódio não está indicado, pois o paciente não se apresenta em acidose metabólica. Em relação aos diuréticos, no caso de um doente renal crônico, pode-se usar um diurético de alça, mas não se espera um efeito tão positivo quanto de um paciente com boa função renal. Inclusive, nestes, com TFG > $30 \mathrm{~mL} / \mathrm{min}$, pode-se usar diuréticos tiazídicos, tendo boa resposta. E no caso de o paciente piorar e os fármacos não funcionarem, a diálise está indicada como emergência. Nessa modalidade de tratamento, prefere-se a hemodiálise que é capaz de remover mais potássio num mesmo período, quando comparado à diálise peritoneal.

\section{Referências}

1. Vendrame LS, Lopes RD. Distúrbios do Sódio. In: Lopes AC. Clínica médica: diagnóstico e tratamento. São Paulo: Editora Atheneu; 2013. p. 1897-921.

2. Gumz ML, Rabinowitz L, Wingo CS. An Integrated View of Potassium Homeostasis. N Engl J Med 2015; 373(1): 60-72.

3. Palmer BF, Clegg DJ. Physiology and pathophysiology of potassium homeostasis. Adv Physiol Educ 
2016; 40(4): 480-90.

4. Medford-Davis L, Rafique Z. Derangements of Potassium. Emerg Med Clin N Am 2014; 32(2):329_ 47.

5. Viera AJ, Wouk N. Potassium Disorders: Hypokalemia and Hyperkalemia. Am Fam Phys 2015; 92(6): 487-95.

6. Hamill RJ, Robinson LM, Wexler HR, Moote C. Efficacy and safety of potassium infusion therapy in hypokalemic critically ill patients. Crit Care Med 1991; 19(5): 694.

7. Montford JR, Linas S. How Dangerous Is Hyperkalemia? J Am Soc Nephrol 2017; 28(11): 3155-65.

8. Palmer BF, Clegg DJ. Diagnosis and treatment of hyperkalemia. Clev Clin J Med 2017; 84 (12): 934-42. 